\title{
Spectroscopic identification of ethanol-water conformers by large-amplitude hydrogen bond librational modes
}

\author{
Andersen, Jonas; Heimdal, J.; Larsen, René Wugt
}

Published in:

Journal of Chemical Physics

Link to article, DOI:

$10.1063 / 1.4937482$

Publication date:

2015

Document Version

Publisher's PDF, also known as Version of record

Link back to DTU Orbit

Citation (APA):

Andersen, J., Heimdal, J., \& Larsen, R. W. (2015). Spectroscopic identification of ethanol-water conformers by large-amplitude hydrogen bond librational modes. Journal of Chemical Physics, 143(22), [224315].

https://doi.org/10.1063/1.4937482

\section{General rights}

Copyright and moral rights for the publications made accessible in the public portal are retained by the authors and/or other copyright owners and it is a condition of accessing publications that users recognise and abide by the legal requirements associated with these rights.

- Users may download and print one copy of any publication from the public portal for the purpose of private study or research.

- You may not further distribute the material or use it for any profit-making activity or commercial gain

- You may freely distribute the URL identifying the publication in the public portal

If you believe that this document breaches copyright please contact us providing details, and we will remove access to the work immediately and investigate your claim 


\section{A|P| $\begin{aligned} & \text { The Journal of } \\ & \text { Chemical Physics }\end{aligned}$}

\section{Spectroscopic identification of ethanol-water conformers by large-amplitude hydrogen bond librational modes}

J. Andersen, J. Heimdal, and R. Wugt Larsen

Citation: The Journal of Chemical Physics 143, 224315 (2015); doi: 10.1063/1.4937482

View online: $\mathrm{http}: / / d x$. doi.org/10.1063/1.4937482

View Table of Contents: http://scitation.aip.org/content/aip/journal/jcp/143/22?ver=pdfcov

Published by the AIP Publishing

\section{Articles you may be interested in}

The effect of large amplitude motions on the vibrational intensities in hydrogen bonded complexes

J. Chem. Phys. 142, 094304 (2015); 10.1063/1.4913737

The effect of hydrogen bonding on torsional dynamics: A combined far-infrared jet and matrix isolation study of methanol dimer

J. Chem. Phys. 141, 174314 (2014); 10.1063/1.4900922

Computational study of hydrogen-bonded complexes of $\mathrm{HOCO}$ with acids: $\mathrm{HOCO} \cdots \mathrm{HCOOH}$,

$\mathrm{HOCO} \cdots \mathrm{H} 2 \mathrm{SO} 4$, and $\mathrm{HOCO} \cdots \mathrm{H} 2 \mathrm{CO} 3$

J. Chem. Phys. 137, 064319 (2012); 10.1063/1.4742817

Cooperative organic hydrogen bonds: The librational modes of cyclic methanol clusters

J. Chem. Phys. 125, 154314 (2006); 10.1063/1.2358349

Quantum-chemical study of $\mathrm{C} \mathrm{H} \mathrm{Cl} 3$ - S O 2 association

J. Chem. Phys. 123, 204311 (2005); 10.1063/1.2121609

\section{AIP $\left.\right|_{\text {APL Photonics }}$}

APL Photonics is pleased to announce Benjamin Eggleton as its Editor-in-Chief

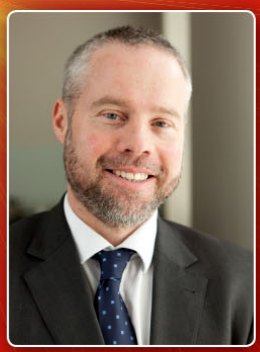




\title{
Spectroscopic identification of ethanol-water conformers by large-amplitude hydrogen bond librational modes
}

\author{
J. Andersen, ${ }^{1}$ J. Heimdal, ${ }^{2}$ and R. Wugt Larsen ${ }^{1, a)}$ \\ ${ }^{1}$ Department of Chemistry, Technical University of Denmark, Kemitorvet 206, 2800 Kongens Lyngby, Denmark \\ ${ }^{2}$ MAX-IV Laboratory, Lund University, P.O. Box 118, 22100 Lund, Sweden
}

(Received 2 November 2015; accepted 27 November 2015; published online 14 December 2015)

\begin{abstract}
The far-infrared absorption spectra have been recorded for hydrogen-bonded complexes of water with ethanol embedded in cryogenic neon matrices at $2.8 \mathrm{~K}$. The partial isotopic $\mathrm{H} / \mathrm{D}$-substitution of the ethanol subunit enabled by a dual inlet deposition procedure enables the observation and unambiguous assignment of the intermolecular high-frequency out-of-plane and the low-frequency in-plane donor $\mathrm{OH}$ librational modes for two different conformations of the mixed binary ethanol/water complex. The resolved donor $\mathrm{OH}$ librational bands confirm directly previous experimental evidence that ethanol acts as the $\mathrm{O} \cdots \mathrm{HO}$ hydrogen bond acceptor in the two most stable conformations. In the most stable conformation, the water subunit forces the ethanol molecule into its less stable gauche configuration upon dimerization owing to a cooperative secondary weak $\mathrm{O} \cdots \mathrm{HC}$ hydrogen bond interaction evidenced by a significantly blue-shift of the low-frequency in-plane donor $\mathrm{OH}$ librational band origin. The strong correlation between the low-frequency in-plane donor $\mathrm{OH}$ librational motion and the secondary intermolecular $\mathrm{O} \cdots \mathrm{HC}$ hydrogen bond is demonstrated by electronic structure calculations. The experimental findings are further supported by CCSD(T)-F12/aug-cc-pVQZ calculations of the conformational energy differences together with second-order vibrational perturbation theory calculations of the large-amplitude donor OH librational band origins. (C) 2015 AIP Publishing LLC. [http://dx.doi.org/10.1063/1.4937482]
\end{abstract}

\section{INTRODUCTION}

A long-standing challenge for the physical sciences is to accurately describe how remarkable macroscopic properties of condensed phases, biological systems, and materials emerge from the interplay between the different classes of non-covalent intermolecular interactions such as directional hydrogen bonding, long-range London dispersion interactions, and short-range steric repulsion between molecules. These different classes of non-covalent interactions are both responsible for the thermodynamic anomalies associated with bulk liquid mixtures, the three-dimensional folding dynamics for biological macromolecules, and the mechanical properties of many functional materials.

In the context of biological systems, the interplay between multiple intermolecular organic hydrogen bond interactions ranging from weak $\mathrm{O} \cdots \mathrm{HC}$ and $\pi \cdots \mathrm{HO}\left(<5-20 \mathrm{~kJ} \mathrm{~mol}^{-1}\right)$ to stronger classical $\mathrm{O} \cdots \mathrm{HO}\left(\sim 20-60 \mathrm{~kJ} \mathrm{~mol}^{-1}\right)$ hydrogen bonds often governs the functionality of many biological macromolecules as these directional intermolecular interactions are able to control the formation of specific enzymesubstrate complexes. For this reason, mixed hydrogen-bonded molecular complexes involving the simplest flexible alcohols are particular interesting model systems since both strong intermolecular $\mathrm{O} \cdots \mathrm{HO}$ hydrogen bonds and weak secondary intermolecular $\mathrm{O} \cdots \mathrm{HC}$ hydrogen bond interactions are

\footnotetext{
a) Author to whom correspondence should be addressed. Electronic mail: rewl@kemi.dtu.dk
}

realized simultaneously. The binary mixed complex of the simplest flexible alcohol, ethanol, with water can be regarded as a prototypical target system which is still amenable to high levels of theoretical ab initio methodologies. This 1:1 ethanol/water complex has turned out to represent one of the simplest mixed hydrogen-bonded molecular complexes of a flexible subunit where the intermolecular hydrogen bond formation affects the internal conformational degrees of freedom. The isolated ethanol molecule exists both in a trans (denoted $t$ ) and in two enantiomeric gauche configurations (denoted $g^{+}$and $g^{-}$) being $\approx 0.5 \mathrm{~kJ} \mathrm{~mol}^{-1}$ higher in electronic energy. ${ }^{1-4}$ Upon complexation with water, several studies have suggested that the ethanol molecule is forced into the less stable gauche configuration.

A sensitive and well-established spectroscopic probe for hydrogen-bonded molecular complexes is the vibrational $\mathrm{OH}-$ stretching manifold of the donor subunits ${ }^{5,6}$ and a recent combined infrared and Raman investigation has monitored the donor $\mathrm{OH}$-stretching spectral red-shifts for mixed 1:1 complexes of water with methanol and ethanol adiabatically cooled in supersonic jet expansions. ${ }^{7,8}$ The vibrational assignments confirmed microwave molecular beam studies ${ }^{9}$ that water acts as the hydrogen bond donor in the most stable conformations of both mixed alcohol/water complexes. ${ }^{7}$ Based on the lower limit of the effective conformational temperature in the supersonic jet expansions of $10 \mathrm{~K}$, the energy difference between the two most stable conformations of the mixed ethanol/water complex has been estimated to be higher than $0.2 \mathrm{~kJ} \mathrm{~mol}^{-1}$ from dedicated collisional relaxation 
experiments. ${ }^{8}$ However, a recent microwave molecular beam work ${ }^{9}$ has only identified the single conformation with ethanol as the hydrogen bond acceptor in the $g^{+}$configuration and more experimental evidence has been welcomed to shed more light on this internal conformational isomerism issue.

In a recent work, it was demonstrated how the strength, directionality, and anharmonicity of mixed alcohol/water complexes can be probed more directly via the largeamplitude intermolecular donor $\mathrm{OH}$ librational modes. These direct spectroscopic observables detected in the challenging far-infrared spectral region between 300 and $600 \mathrm{~cm}^{-1}$ have been shown to enable an accurate characterization of the intermolecular potential energy landscape between the hydrogen bond partners. ${ }^{10-13}$ Its nature as a localized motion of the donor hydrogen atom makes the high-frequency outof-plane donor $\mathrm{OH}$ librational mode an excellent probe for the intermolecular hydrogen bond interaction in a similar fashion as the Badger-Bauer relationship associated with the bathochromic shift of the intramolecular donor vibrational $\mathrm{OH}$-stretching mode. ${ }^{14} \mathrm{~A}$ stronger intermolecular hydrogen bond results in a more hindered internal rotational motion and an increase of the band origin for this high-frequency hydrogen bond donor mode. In the mixed complexes of water with aliphatic alcohols, these donor $\mathrm{OH}$ librational spectral signatures thus act as a measure of the hydrogen bond acceptor strength of the alcohol molecule. In the present work, we demonstrate how the low-frequency inplane donor $\mathrm{OH}$ librational mode of mixed ethanol/water complexes, essentially a hindered overall $c$-axis rotation of the water subunit, provides an excellent probe for the cooperative secondary $\mathrm{O} \cdots \mathrm{HC}$ hydrogen bond interactions, which allows for a rigorous benchmarking of theory.

\section{EXPERIMENTAL}

A pre-cooled $(77 \mathrm{~K})$ gas flow of neon (L'Air Liquide, $99.999 \%$ ) was deposited with a flow rate of $0.02 \mathrm{~mol} / \mathrm{h}$ on a gold-plated oxygen-free high thermal conductivity (OFHC) copper mirror at $3.6 \mathrm{~K}$ inside an immersion helium cryostat (IHC-3) modified for matrix isolation spectroscopy. ${ }^{13,15}$ The pre-cooling of neon significantly reduces the heat load on the copper mirror and enables a total deposition time of 1-2 $\mathrm{h}$ per experiment. The pre-cooled neon gas flow was subsequently doped with "freeze-pump-thaw" purified $\mathrm{C}_{2} \mathrm{H}_{5} \mathrm{OH}$ (Sigma Aldrich, 99.9\%), and $\mathrm{H}_{2} \mathrm{O}$ (Milli-Q) samples and isotopically substituted $\mathrm{C}_{2} \mathrm{H}_{5} \mathrm{OH}-\mathrm{d} 1$ (Sigma Aldrich, 99.0\% D), $\mathrm{C}_{2} \mathrm{H}_{5} \mathrm{OH}-$ d6 (Sigma Aldrich, 99.0\% D) and $\mathrm{D}_{2} \mathrm{O}$ (Sigma Aldrich, $99.5 \%$ D) samples via separate inlet tubes with mixing ratios of $\simeq 0.5-5$ permille. The combination of resistive heaters and feedback electronics was employed to maintain a stable mirror temperature at $2.8 \pm 0.1 \mathrm{~K}$ before and after the neon matrix depositions. The cold head was mounted with interchangeable CsI and polymethylpentene (TPX) windows and combined IR and $\mathrm{THz}$ single-beam sample spectra were collected by a Bruker IFS 120 FTIR spectrometer employing tungsten and globar lamps as the radiation sources. Liquid nitrogen cooled $\mathrm{HgCdTe}$ (broadband) and InSb detectors combined with $\mathrm{Ge} / \mathrm{KBr}$ and $\mathrm{CaF}_{2}$ beam splitters, respectively, were employed for the spectral region above $600 \mathrm{~cm}^{-1}$. A Sibolometer operating at $4.2 \mathrm{~K}$ combined with a $6 \mu \mathrm{m}$ multilayer Mylar beam splitter was employed for the $30-650 \mathrm{~cm}^{-1}$ spectral region. In all experiments, the doped neon matrices were annealed up to $9 \mathrm{~K}$ for the study of temperature effects. Single-beam background spectra were subsequently collected of the evacuated cryostat. A spectral resolution in the range from 0.1 to $1.0 \mathrm{~cm}^{-1}$ was selected depending on the observed band widths.

\section{VIBRATIONAL ASSIGNMENTS FOR THE MIXED ETHANOL/WATER COMPLEX}

Figs. 1 and 2 show selected spectral regions from a series of far-infrared absorption spectra $\left(200-600 \mathrm{~cm}^{-1}\right)$ collected for several millimeter thick cryogenic neon matrices doped with pure water $\left(\mathrm{H}_{2} \mathrm{O}: \mathrm{Ne}\right)=(1: 1700)$, pure ethanol $\left(\mathrm{C}_{2} \mathrm{H}_{5} \mathrm{OH}: \mathrm{Ne}\right)=(1: 1200)$, and different isotopically substituted ethanol/water mixtures $\left(\mathrm{C}_{2} \mathrm{H}_{5} \mathrm{OH}: \mathrm{H}_{2} \mathrm{O}: \mathrm{Ne}\right)$ $=(2: 1: 1700)$ at $2.8 \mathrm{~K}$. In previous far-infrared matrix isolation studies of water embedded in neon, the pure complexes of water have been explored extensively. ${ }^{13,16-19}$ In the spectral region above $300 \mathrm{~cm}^{-1}$, the strong intermolecular highfrequency out-of-plane and low-frequency in-plane donor $\mathrm{OH}$ librational bands of the water dimer embedded in neon matrices have previously been assigned at $522.4 \mathrm{~cm}^{-1}$ and $309.1 \mathrm{~cm}^{-1}$ (Fig. 1), respectively. ${ }^{16}$ The low-frequency donor in-plane $\mathrm{OH}$ librational band is slightly overlapped with the $c$ axis librational band of cyclic water trimer previously assigned at $310.8 \mathrm{~cm}^{-1}$. In addition, a number of five combination bands have previously been observed for the cyclic water trimer where the strongest transitions have been assigned at $280.0,386.8$ and $414.1 \mathrm{~cm}^{-1} .{ }^{17}$

The absorption spectrum of ethanol below $300 \mathrm{~cm}^{-1}$ has been widely studied by both experiment and theory owing to the trans-gauche isomerism and the proximity

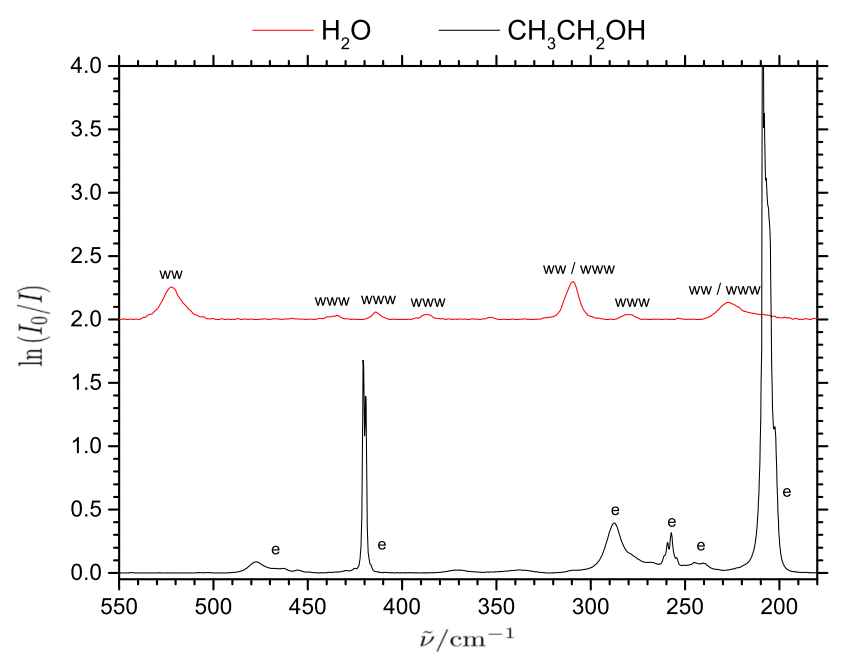

FIG. 1. The observed far-infrared absorption spectra $\left(200-550 \mathrm{~cm}^{-1}\right)$ of pure water and pure ethanol embedded in neon matrices at $2.8 \mathrm{~K}$. The vibrational assignments for the ethanol monomer is denoted $e$ and the vibrational assignments for the water complexes are denoted $w w$ (dimer) and $w w w$ (trimer), respectively. 


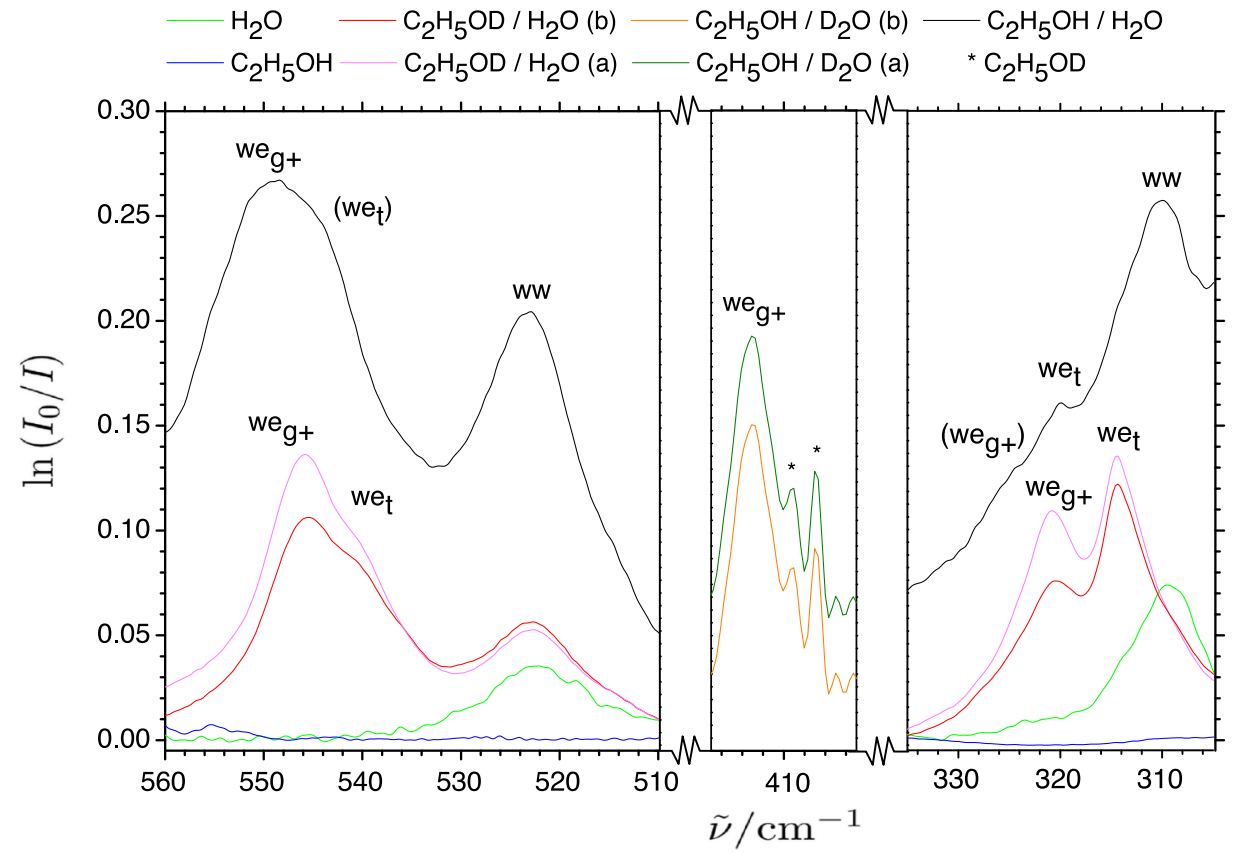

FIG. 2. The observed far-infrared absorption spectra of pure water, pure ethanol, and different isotopic ethanol/water mixtures embedded in neon matrices at $2.8 \mathrm{~K}$ before annealing (b) and after annealing (a) to $9 \mathrm{~K}$ in the spectral regions belonging to the out-of-plane $\mathrm{OH}$ (left), out-of-plane $\mathrm{OD}$ (center), and in-plane $\mathrm{OH}$ (right) donor librational modes. The proposed vibrational assignments for the mixed isotopic complexes of water $(w)$ and ethanol $(e)$ in the trans and gauche+ conformations are denoted $w e_{t}$ and $w e_{g_{+}}$, respectively (see text), whereas the vibrational assignments for the water dimer is denoted as $w w$. The asterisks denote traces of ethanol-d1 impurities.

and the large vibrational amplitudes for the $\mathrm{OH}$ and $\mathrm{CH}_{3}$ torsional motion of this molecule. ${ }^{1,2,20-24}$ A previous work has addressed the complex asymmetric top-asymmetric frame internal rotation spectrum of the flexible ethanol monomer and cites the numerous previous microwave investigations employed to characterize the vibrational ground state and the conformational trans-gauche isomerism of ethanol. ${ }^{22} \mathrm{We}$ also refer to this comprehensive work for further details about the excited energy sub-levels of ethanol associated with the large-amplitude $\mathrm{OH}$ and $\mathrm{CH}_{3}$ torsional degrees of freedom which has been complemented by far-infrared gas-phase absorption spectroscopy ${ }^{1,21}$ and more recently by Raman jet spectroscopy. ${ }^{23}$ The gas-phase absorption study assigned a single band observed at $202.6 \mathrm{~cm}^{-1}$ to the fundamental $\mathrm{OH}$ torsional transition of the trans conformation and two other bands observed at 195.8 and $243.1 \mathrm{~cm}^{-1}$ to the gauche conformation $\left(g^{+} \leftarrow g^{-}\right.$and $g^{-} \leftarrow g^{+}$transitions, respectively). The Raman jet study assigned two other bands observed at $199.1 \mathrm{~cm}^{-1}\left(g^{+} \leftarrow g^{+}\right)$and $240 \mathrm{~cm}^{-1}$ $\left(g^{-} \leftarrow g^{-}\right){ }^{23}$ The far-infrared absorption spectrum of ethanol embedded in cryogenic argon matrices has previously just revealed two strong transitions observed at 211 and $264 \mathrm{~cm}^{-1}$ besides the strong $\mathrm{CCO}$ bending fundamental transition at $416.5 \mathrm{~cm}^{-1} .^{20}$ In the present far-infrared spectra of ethanol embedded in more inert cryogenic neon matrices, a series of weak, medium-intensity, and strong bands are observed besides the strong $\mathrm{CCO}$ bending fundamental transition at $419.9 \mathrm{~cm}^{-1}$ (Fig. 1). A strong sharp transition appears at $208.9 \mathrm{~cm}^{-1}$ with two less intense shoulders observed at $206.5 \mathrm{~cm}^{-1}$ and $202.4 \mathrm{~cm}^{-1}$. The spectra further reveal a broad medium-intense band at $287.4 \mathrm{~cm}^{-1}$, a medium-intense band structure around $258 \mathrm{~cm}^{-1}$, and a weaker band structure around $243 \mathrm{~cm}^{-1}$. These observed spectral features are in qualitative agreement with the coupled $\mathrm{OH}$ and $\mathrm{CH}_{3}$ torsional sub-bands predicted previously from a two-dimensional $a b$ initio Hamiltonian. ${ }^{24}$ A more detailed interpretation of the observed spectral features is beyond the scope of the present work concerned with the donor $\mathrm{OH}$ librational modes of the mixed ethanol/water complex. Both the partial and complete $\mathrm{H} / \mathrm{D}$ substitution of ethanol red-shifts the disturbing torsional sub-band component at $287.4 \mathrm{~cm}^{-1}$ to below $200 \mathrm{~cm}^{-1}$ and thereby paves the way for the spectral region between 300 and $600 \mathrm{~cm}^{-1}$.

The far-infrared spectra recorded for neon matrices doped with regular ethanol and regular water simultaneously at moderate concentrations reveal new distinct bands in the close vicinity to the high-frequency out-of-plane and lowfrequency in-plane donor $\mathrm{OH}$ librational bands of water dimer. A weak band seems to emerge around $320 \mathrm{~cm}^{-1}$ on the shoulder of the in-plane donor $\mathrm{OH}$ librational band of water dimer at $309.1 \mathrm{~cm}^{-1}$ (Fig. 2, right inset). This spectral region is still affected by the broad torsional subband component of ethanol observed in the neon matrices at $287.4 \mathrm{~cm}^{-1}$. In addition, a stronger and more distinct but somewhat broader band clearly emerges in the spectrum at $551.6 \mathrm{~cm}^{-1}$ for neon matrices doped with ethanol and water (Fig. 2, left inset). Both observed bands and in particular the latter band at $551.6 \mathrm{~cm}^{-1}$ are thus blue-shifted relative to the established donor $\mathrm{OH}$ librational transitions of the water dimer (Table I). This observation supports the trend from the previous investigation of mixed binary complexes of water with methanol and $t$-butanol embedded in cryogenic neon matrices. ${ }^{25}$ This previous work has established that water acts as the hydrogen bond donor in the most stable binary mixed complexes with methanol and $t$-butanol. This hydrogen bond donor/acceptor relationship gives rise to similar outof-plane and in-plane donor $\mathrm{OH}$ librational motions for the mixed alcohol/water complexes as observed for the donor subunit in the water dimer. The animated donor $\mathrm{OH}$ librational normal mode pictures are shown for the mixed ethanol/water complex in Fig. 3. The high-frequency out-of-plane donor $\mathrm{OH}$ libration can be described as a localized motion of the "bound" hydrogen atom. This localized mode turns out to be an excellent probe for the intermolecular hydrogen bond 
TABLE I. The observed high-frequency out-of-plane and low-frequency in-plane donor OH (OD) librational band origins $\left(\mathrm{cm}^{-1}\right)$ for the water dimer and the two most stable isotopic complexes of water $(w)$ and ethanol $(e)$ in the trans (denoted $w e_{t}$ ) and gauche+ (denoted $w e_{g+}$ ) conformations embedded in neon matrices at $2.8 \mathrm{~K}$.

\begin{tabular}{lccccc}
\hline \hline Donor-acceptor & $v_{\text {lib, out-of-plane }}$ & $v_{\text {lib, in-plane }}$ & Donor-acceptor & $v_{\text {lib,out-of-plane }}$ & $v_{\text {lib, in-plane }}$ \\
\hline$w w$ & $522.4^{\mathrm{a}}$ & $309.1^{\mathrm{a}}$ & $w(\mathrm{~d} 2) w(\mathrm{~d} 2)$ & $393.2^{\mathrm{a}}$ & $233.5^{\mathrm{a}}$ \\
$w e_{g+}$ & 551.6 & 324.7 & $w(\mathrm{~d} 2) e_{g+}$ & 412.5 & 239.6 \\
$w e_{t}$ & $(545.4)^{\mathrm{b}}$ & $(320.4)^{\mathrm{b}}$ & $w(\mathrm{~d} 2) e_{t}$ & $\mathrm{c}$ & $\mathrm{c}$ \\
$w e_{g+}(\mathrm{d} 1)$ & 545.6 & 320.9 & $w(\mathrm{~d} 2) e_{g+}(\mathrm{d} 1)$ & $\mathrm{d}$ & 238.2 \\
$w e_{t}(\mathrm{~d} 1)$ & 541.1 & 314.7 & $w(\mathrm{~d} 2) e_{t}(\mathrm{~d} 1)$ & $\mathrm{c}$ & $\mathrm{c}$ \\
$w e_{g+}(\mathrm{d} 6)$ & 545.6 & 320.9 & & & \\
$w e_{t}(\mathrm{~d} 6)$ & 540.1 & 313.9 & & & \\
\hline \hline
\end{tabular}

\footnotetext{
${ }^{\mathrm{a}}$ Ceponkus et al. ${ }^{13}$

${ }^{\mathrm{b}}$ Tentative assignments due to strong overlaps with $w \boldsymbol{e}_{g+}$.

${ }^{\mathrm{c}}$ Not observed.

${ }^{\mathrm{d}}$ Overlap with the CCO bending mode of ethanol-d1.
}

interaction $^{10,11,25}$ in the same way as the pronounced redshift of the intramolecular donor $\mathrm{OH}$-stretching mode. The observed high-frequency out-of-plane $\mathrm{OH}$ librational band origin of $551.6 \mathrm{~cm}^{-1}$ thus indicates a significantly stronger intermolecular hydrogen bond for the mixed ethanol/water complex than the corresponding mixed methanol/water complex having a band origin of $527.5 \mathrm{~cm}^{-1}$ but a slightly weaker hydrogen bond than for the mixed $t$-butanol/water complex having a band origin of $556.6 \mathrm{~cm}^{-1} .{ }^{25}$ These preliminary and entirely spectroscopic interpretations about the relative hydrogen bond energies shall be supported with predictions from exploratory quantum chemical calculations in the theoretical section. A few other experimental studies for mixed water complexes with methanol and ethanol embedded in cryogenic matrices of nitrogen and argon have been reported in Refs. 26 and 27. In the most perturbing matrix environment of nitrogen, a reversed hydrogen bond donor/acceptor relationship for the alcohol/water complexes has been observed although severe site effects blurred the observed spectral signatures. This has been explained by weak cooperative attractive interactions between the $\mathrm{OH}$ groups and the $\mathrm{N}_{2}$ host molecules. ${ }^{28}$ In the mixed complexes where the alcohol molecule acts as the hydrogen bond donor, both dangling $\mathrm{OH}$ groups of the water acceptor subunit might interact with $\mathrm{N}_{2}$ host molecules and thereby increasing the acceptor character of the $\mathrm{O}$ nuclei on the water molecule. This

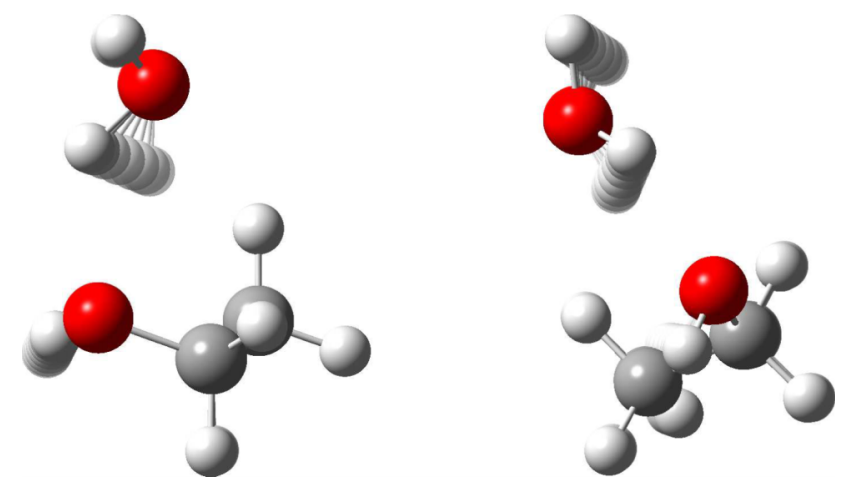

FIG. 3. Normal mode pictures of the large-amplitude high-frequency out-ofplane (left) and low-frequency in-plane (right) donor $\mathrm{OH}$ librational modes of the most stable conformation of the mixed hydrogen-bonded ethanol/water complex (see text). effect might strengthen the intermolecular interaction to the alcohol subunit and overcome the energy barrier between the different alcohol-water conformers. ${ }^{28}$

The dual inlet deposition procedure designed for partial isotopic $\mathrm{H} / \mathrm{D}$ substitutions of the individual subunits enables the unambiguous identification of the proposed hydrogen bond donor/acceptor roles in the cryogenic neon environment. The $\mathrm{H} / \mathrm{D}$ substitution on the water subunit introduces a significant red-shift from $551.6 \mathrm{~cm}^{-1}$ to $412.5 \mathrm{~cm}^{-1}$ which further confirms that water acts as hydrogen bond donor (Fig. 2, central inset). The observed $\mathrm{OH} / \mathrm{OD}$ band origin ratio of 1.34 is rather close to the theoretical value of $\sqrt{2}$ expected for a localized harmonic hydrogen motion and supports an assignment to the out-of-plane donor OD librational mode for the complex of $\mathrm{D}_{2} \mathrm{O}$ with ethanol. This band origin is slightly larger than the corresponding donor OD librational band origin assigned previously at $397.6 \mathrm{~cm}^{-1}$ for the less stable mixed complex of methanol with $\mathrm{D}_{2} \mathrm{O}$ embedded in neon. ${ }^{25}$ The low-frequency in-plane donor OD librational mode is shifted into the congested spectral region belonging to the coupled $\mathrm{OH}$ and methyl torsional modes of ethanol making the assignment of this band difficult although a tentative assignment can be proposed at $239.6 \mathrm{~cm}^{-1}$ (not shown). A similar partial H/D substitution on ethanol deposited with regular water introduces solely a small red-shift of $6 \mathrm{~cm}^{-1}$ for the high-frequency donor $\mathrm{OH}$ librational band supporting the proposed hydrogen bond acceptor role of the ethanol subunit (Fig. 2, left inset). The farinfrared spectra for ethanol-d1/water mixtures doped in neon, however, all seem to contain two distinct bands at $545.6 \mathrm{~cm}^{-1}$ and $541.1 \mathrm{~cm}^{-1}$ in this spectral region. These observations are supported by subsequent annealing experiments where the mirror temperature is raised to $9 \mathrm{~K}$ to allow the guest molecules to diffuse within the soft neon matrices. The annealing in particular favors the diffusion of the smaller water molecules in the soft neon matrices and the excess of ethanol should thereby trigger the formation of mixed ethanol/water complexes. The post-annealing spectrum recorded after subsequent cooling to $3 \mathrm{~K}$ reveals a significant increase of both band intensities whereas the high-frequency out-of-plane donor $\mathrm{OH}$ librational band of water dimer at $522.9 \mathrm{~cm}^{-1}$ is almost unaffected by annealing (Fig. 2, left inset). The post-annealing intensity of the band observed at $545.6 \mathrm{~cm}^{-1}$ is significantly larger than the post-annealing intensity of the other band observed at 
$541.1 \mathrm{~cm}^{-1}$. This observation suggests that these overlapped bands originate from two conformations of the mixed ethanol$\mathrm{d} 1 /$ water complex with the band at $545.6 \mathrm{~cm}^{-1}$ assigned to the most stable conformation. The partial H/D substitution on the ethanol sample turns out to have an even more pronounced effect on the low-frequency in-plane donor $\mathrm{OH}$ librational signature where two completely separated bands are observed at $320.9 \mathrm{~cm}^{-1}$ and $314.7 \mathrm{~cm}^{-1}$, respectively (Fig. 2, right inset). The post-annealing spectra again reveal a changed relative intensity compared to the pre-annealing spectra. The more significant post-annealing intensity increase of the band observed at $320.9 \mathrm{~cm}^{-1}$ suggests an assignment to the most stable conformation of the mixed ethanol-d1/water complex. In the same fashion, the complete H/D substitution on the ethanol sample enables the identification of two conformations of the mixed ethanol-d6/water complex with band origins red-shifted by less than $1 \mathrm{~cm}^{-1}$ relative to the ethanol-d1/water conformations (see Table I). In order to shed further light on the proposed assignments and clarify the observation of two conformations of the ethanol-d1/water and ethanol-d6/water complexes, we consult exploratory electronic structure calculations.

\section{EXPLORATORY QUANTUM CHEMICAL CALCULATIONS}

The quantum chemical software packages Gaussian09 (Rev. D.01) $)^{29}$ and Turbomole (ver. 6.6) (30,31 $^{30}$ have both been employed for $a b$ initio molecular orbital and supplementary density functional theory (DFT) calculations. The equilibrium geometries of the water and ethanol subunits and the different conformations of the mixed ethanol-water complexes were all optimized and the corresponding electronic energies calculated employing the canonical B3LYP level, ${ }^{32}$ the dispersion-corrected B3LYP-D3 approach, ${ }^{33}$ and the second order Möller-Plesset (MP2) methodology ${ }^{34,35}$ coupled with Dunning's augmented correlation-consistent triple-zeta (augcc-pVTZ) and quadruple-zeta (aug-cc-pVQZ) basis sets. ${ }^{36}$ The root-mean-square force criterion has been set to $10^{-6}$ (atomic units) for all the equilibrium geometry optimizations. The electronic energies for these optimized equilibrium geometries were subsequently calculated employing both the canonical and the explicitly correlated coupled-cluster approaches with single and double with perturbative triple excitations, $\operatorname{CCSD}(\mathrm{T})^{37}$ and $\operatorname{CCSD}(\mathrm{T})-\mathrm{F} 12{ }^{38}$ in order to optimize the extent of electron correlation in combination with the same Dunning basis sets. The basis set superposition errors ${ }^{39}$ have been accounted for by the counterpoise method of Boys and Bernardi. ${ }^{40}$ The harmonic vibrational frequencies and overall vibrational zero-point energy (ZPE) contributions for the monomers and ethanol-water conformations have been calculated employing the doubly harmonic approximation whereas the anharmonic frequencies have been calculated using the VPT2 approach ${ }^{41}$ as implemented in Gaussian09 (Rev. D.01). ${ }^{29}$ In a series of calculations, the secondary $\mathrm{CH} \cdots \mathrm{O}$ hydrogen bond contact between the terminal $\mathrm{CH}$ group on the ethanol subunit and the lone pair of the water subunit was kept fixed (Keyword $=$ ModRedundant) in the geometry optimization in order to investigate the dependence of the donor $\mathrm{OH}$-stretching and donor $\mathrm{OH}$ librational frequencies on this intermolecular $\mathrm{CH} \cdots \mathrm{O}$ contact strength.

\section{DISCUSSION}

\section{A. Hydrogen-bonded conformations of the mixed ethanol/water complex}

In line with previous theoretical predictions of the intermolecular potential energy landscape for the binary ethanol/water complex, ${ }^{7,9}$ five distinguishable conformations have been investigated. Fig. 4 illustrates the relative electronic binding energy $D_{0}$ calculated with the $\operatorname{CCSD}(\mathrm{T})$-F12/augcc-pVQZ approach for these five most stable conformations optimized at the MP2/aug-cc-pVQZ level of theory. The changes of the harmonic vibrational zero-point energy upon complexation ( $\triangle \mathrm{ZPE}$ ) have been calculated at the MP2/augcc-pVTZ level of theory. This combined methodology is regarded as the benchmark level of theory as illustrated by the series of predictions of the electronic binding energy $D_{e}$ for the most stable mixed complex of water with ethanol listed in Table II. The listed predictions provide the results from combined quantum chemical methodologies employed for the geometry optimizations and subsequent single-point electronic energy calculations. These computations show that the canonical B3LYP functional ${ }^{32}$ underestimates the binding

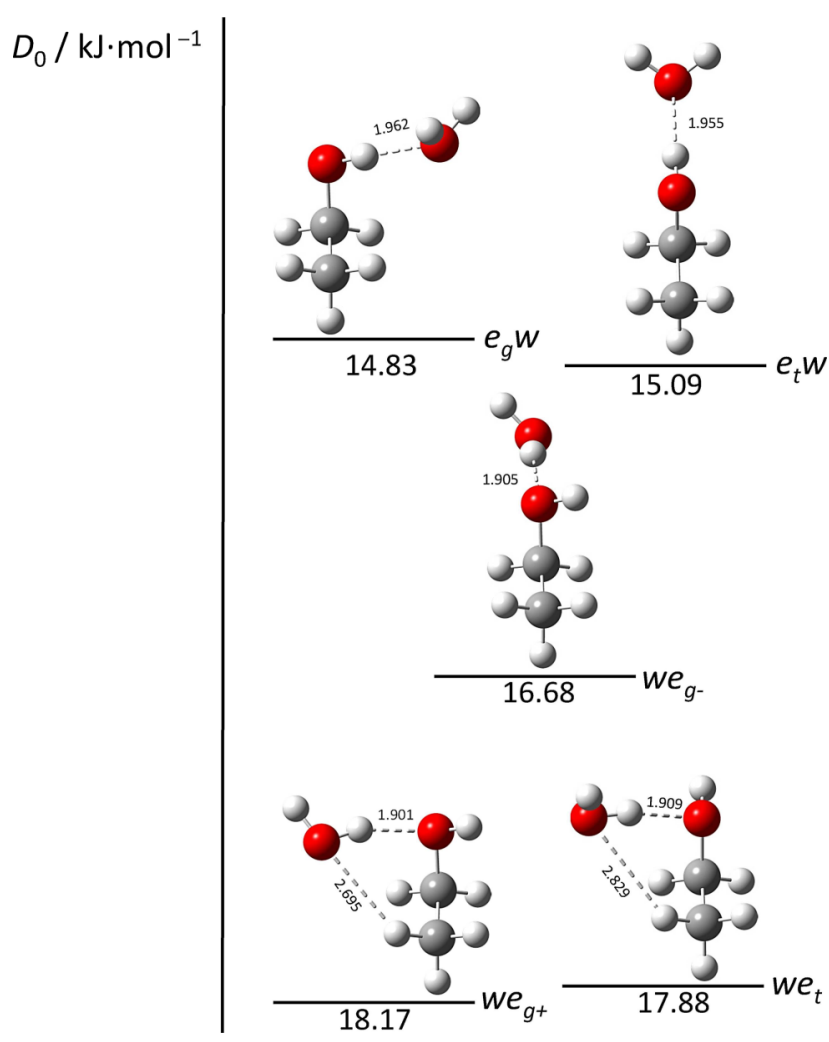

FIG. 4. The intermolecular potential energy landscape including the most stable conformations of the mixed 1:1 complex of ethanol and water in terms of the electronic binding energies $D_{0}$ calculated employing the $\operatorname{CCSD}(\mathrm{T})$ F12/aug-cc-pVQZ approach for the five most stable conformations optimized at the MP2/aug-cc-pVQZ level of theory (see text). 
TABLE II. The electronic dissociation energy $D_{e}$ of the two most stable conformations of the ethanol/water complex (denoted $w e_{g}+$ and $w e_{t}$ ) and the difference of electronic dissociation energy between the conformations $\Delta E_{e}=D_{e}\left(w e_{g+}\right)-D_{e}\left(w e_{t}\right)$ predicted from combined quantum chemical methodologies for the geometry optimization and electronic energy calculations employing Dunning's augmented correlation-consistent triple zeta (aug-cc-pVTZ) and quadruple zeta (aug-cc-pVQZ) basis sets.

\begin{tabular}{llcc}
\hline \hline Optimization $^{\mathrm{a}}$ & \multicolumn{1}{c}{ Electronic energy } & $D_{e}\left(w e_{g}+\right) / \mathrm{kJ} \mathrm{mol}^{-1}$ & $\Delta E_{e} / \mathrm{kJ} \mathrm{mol}^{-1}$ \\
\hline B3LYP/aug-cc-pVTZ & B3LYP/aug-cc-pVTZ & 20.99 & 0.03 \\
B3LYP-CP/aug-cc-pVTZ & B3LYP/aug-cc-pVTZ & 20.69 & 0.04 \\
B3LYP-CP/aug-cc-pVTZ & CCSD(T)/aug-cc-pVTZ & 26.33 & 0.03 \\
B3LYP-D3/aug-cc-pVTZ & B3LYP-D3/aug-cc-pVTZ & 28.02 & 0.61 \\
B3LYP-D3-CP/aug-cc-pVTZ & B3LYP-D3/aug-cc-pVTZ & 27.68 & 0.62 \\
B3LYP-D3-CP/aug-cc-pVTZ & CCSD(T)/aug-cc-pVTZ & 27.96 & 0.48 \\
MP2/aug-cc-pVTZ & MP2/aug-cc-pVTZ & 27.27 & 0.36 \\
MP2-CP/aug-cc-pVTZ & MP2/aug-cc-pVTZ & 24.52 & 0.37 \\
MP2-CP/aug-cc-pVTZ & CCSD(T)/aug-cc-pVTZ & 27.46 & 0.54 \\
MP2-CP/aug-cc-pVTZ & CCSD(T)-F12/aug-cc-pVTZ & 27.01 & 0.58 \\
MP2/aug-cc-pVQZ & MP2/aug-cc-pVQZ & 26.61 & 0.41 \\
MP2-CP/aug-cc-pVQZ & MP2/aug-cc-pVQZ & 25.24 & 0.40 \\
MP2-CP/aug-cc-pVQZ & CCSD(T)/aug-cc-pVQZ & 26.63 & 0.58 \\
MP2-CP/aug-cc-pVQZ & CCSD(T)-F12/aug-cc-pVQZ & 26.50 & 0.56 \\
\hline \hline
\end{tabular}

${ }^{a}$ RMS force criterion set to $10^{-6}$ (atomic units) for all geometry optimizations.

${ }^{\mathrm{b}} \mathrm{CP}=$ Counterpoise Correction applied.

energy $D_{e}$ for the most stable mixed complex of water with ethanol by ca. $20 \%\left(5.5 \mathrm{~kJ} \mathrm{~mol}^{-1}\right)$ whereas the B3LYPD3 approach including Grimme and co-worker's dispersion corrections ${ }^{33}$ slightly overestimates this binding energy by ca. $5 \%\left(1.5 \mathrm{~kJ} \mathrm{~mol}^{-1}\right)$ relative to the benchmark $D_{e}$-value of $26.5 \mathrm{~kJ} \mathrm{~mol}^{-1}$. This predicted electronic binding energy is significantly larger than the predicted binding energy for the mixed methanol/water complex but slightly smaller than the predicted binding energy for the $t$-butanol/water complex as expected. ${ }^{25}$ The harmonic $\triangle \mathrm{ZPE}$-correction of $8.3 \mathrm{~kJ} \mathrm{~mol}^{-1}$ then translates this value into an absolute electronic binding energy $D_{0}$ of $18.2 \mathrm{~kJ} \mathrm{~mol}^{-1}$ for the most stable conformation of the ethanol/water complex as shown in Fig. 2.

In the three most stable conformations, the water subunit acts as the hydrogen bond donor. These three structures are denoted as we whereas the remaining two structures having ethanol as the hydrogen bond donor are denoted as ew. In the three most stable forms having water as the hydrogen bond donor, not only the conformation (trans or gauche) of the ethanol subunit is relevant but also the choice of the acceptor lone pair on ethanol. In the gauche+ conformation, the $\mathrm{O}-\mathrm{H}$ bond is rotated clockwise by $120^{\circ}$ relative to the trans conformation in the perspective along the $\mathrm{O}-\mathrm{C}$ bond employing a Newman projection. In the conformations of the mixed complex of ethanol with water as the hydrogen bond donor, a new asymmetric center emerges at the oxygen atom of the alcohol subunit due to the two potential acceptor oxygen lone pairs and two potential enantiomeric conformations. Looking again along the $\mathrm{O}-\mathrm{C}$ bond vector, the lone pair in a clockwise direction from the $\mathrm{OH}$ bond is denoted by the right lone pair as shown in Fig. 4 in line with previous works. ${ }^{7,9}$ In the case of two non-distinguishable enantiomeric conformations, we discuss the conformation where this right lone pair is engaged in the hydrogen bond. As illustrated in Fig. 4, the $w e_{g+}$ conformation with a hydrogen bond to the right lone pair of ethanol is predicted to be the most stable and compact conformation of the mixed ethanol/water complex at the benchmark level. In contrast to the third most stable $w e_{g_{-}}$conformation, the $w e_{g_{+}}$conformation is further stabilized by a cooperative secondary hydrogen bond interaction between the terminal $\mathrm{CH}$ group on ethanol and the oxygen lone pair on the water subunit with a contact distance predicted to $2.695 \AA$ at the MP2/aug-cc-pVQZ level (see Fig. 4), although this weaker secondary interaction bends the primary $\mathrm{O} \cdots \mathrm{HO}$ hydrogen bond slightly from a linear arrangement. In the most stable conformation the water subunit thus forces the ethanol hydrogen bond partner into its less stable gauche conformation upon complexation although the trans conformation is the most stable for an isolated ethanol molecule. This is considered as one of the most elementary cases together with hydroxyacetone ${ }^{42}$ of adaptive aggregation, where a non-rigid molecule is forced into a less stable conformation upon non-covalent binding to a hydrogen bond donor molecule to optimize the mutual interaction energy. The second most stable conformation of the mixed complex having water as the hydrogen bond donor and the acceptor ethanol subunit in its trans configuration is also further stabilized by a cooperative secondary $\mathrm{O} \cdots \mathrm{HC}$ contact. However, this secondary interaction is less strong with a contact distance predicted to $2.829 \AA$ at the MP2/aug-cc-pVQZ level (see Fig. 4). The small difference of electronic dissociation energy between these two most stable conformations $\Delta E_{e}=D_{e}\left(w e_{g+}\right)-D_{e}\left(w e_{t}\right)$ listed in Table II seems to depend on the computational methodology. The canonical B3LYP approach predicts almost identical electronic dissociation energies whereas the dispersioncorrected B3LYP-D3 approach slightly overestimates this difference in the electronic dissociation energy relative to the benchmark $\operatorname{CCSD}(\mathrm{T})-\mathrm{F} 12 /$ aug-cc-pVQZ value of $0.56 \mathrm{~kJ} \mathrm{~mol}^{-1}$ for $\Delta E_{e}$. The effect of the ZPE contributions and in particular the influence of the donor $\mathrm{OH}$ librational motion 
on the electronic dissociation energy must be considered before reaching any further conclusions.

\section{B. Vibrational zero-point energy contributions}

The change of vibrational ZPE upon intermolecular hydrogen bond formation is notoriously complicated to predict by quantum chemical methods in particular for the largeamplitude and highly anharmonic intermolecular hydrogen bond librational motions. In a previous combined jet and neon matrix isolation far-infrared study of methanol dimer, the similar high-frequency out-of-plane donor $\mathrm{OH}$ librational band was observed and assigned at $560 \mathrm{~cm}^{-1}{ }^{12}$ This study reported an overall sum of anharmonic contributions to this out-of-plane donor $\mathrm{OH}$ librational fundamental transition in the order of $100 \mathrm{~cm}^{-1}$ by employing vibrational second-order perturbation theory (VPT2) ${ }^{41}$ In the combination with the benchmark harmonic band origin of $660 \mathrm{~cm}^{-1}$ predicted at the $\operatorname{LCCSD}(\mathrm{T})-\mathrm{F} 12$ level, the anharmonic predicted band origin of $560 \mathrm{~cm}^{-1}$ turned out to be in excellent agreement with the experimental neon matrix findings. In a previous investigation of the mixed methanol/water complex, a similar anharmonic VPT2 analysis ${ }^{41}$ at the MP2/aug-cc-pVTZ level also suggested anharmonicity contributions in the order of $15 \%-20 \%$ for the corresponding high-frequency out-of-plane donor $\mathrm{OH}$ librational transition. ${ }^{25}$ In this previous work, standard vibrational frequency calculations at the MP2/augcc-pVTZ level provided harmonic band origins of 647 and $669 \mathrm{~cm}^{-1}$ for the high-frequency out-of-plane donor $\mathrm{OH}$ librational transitions for the mixed complexes of water with methanol and $t$-butanol, respectively. ${ }^{25}$ The ordering of these harmonic values is in qualitative agreement with the previous experimental findings suggesting that similar harmonic predictions for the ethanol/water complex should fit into this picture. The harmonic calculations for the outof-plane donor $\mathrm{OH}$ librational modes of the two most stable ethanol/water conformations at the MP2/aug-cc-pVTZ level indeed predict these band origins between 647 and $669 \mathrm{~cm}^{-1}$ as expected. However, the harmonic band origin for the most stable $w e_{g_{+}}$conformation is predicted at $654 \mathrm{~cm}^{-1}$ with the harmonic band origin for the less stable $w e_{t}$ conformation predicted at $660 \mathrm{~cm}^{-1}$ in contrast to our proposed experimental assignments based on evident annealing effects (see Table I). An anharmonic VPT2 analysis at the MP2/aug-cc-pVTZ level, however, reverses the order of predicted band origins $\left(549 \mathrm{~cm}^{-1}\right.$ for the $w e_{g+}$ conformation and $543 \mathrm{~cm}^{-1}$ for the $w e_{t}$ conformation) and confirms anharmonicity contributions of $15 \%-20 \%$. A similar analysis of the low-frequency inplane donor $\mathrm{OH}$ librational modes and the entire sets of large-amplitude intermolecular vibrational transitions for the non-rigid hydrogen-bonded ethanol/water complex would be to stretch the reliability of the VPT2 approach. Table III thus provides the harmonic vibrational ZPE contribution for mixed isotopic complexes of water with ethanol predicted at the feasible MP2/aug-cc-pVTZ level of theory.

The incorporation of the calculated vibrational ZPE contributions has a large impact as evidenced by the resulting absolute ground-state dissociation energies $D_{0}$ of the different $w e_{t}$ and $w e_{g+}$ conformations listed in Table III. The total
TABLE III. The electronic dissociation energy $D_{e}(\mathrm{CCSD}(\mathrm{T})-\mathrm{F} 12 /$ aug-cc$\left.\mathrm{pVQZ}^{\mathrm{a}}\right)$, the total change of harmonic vibrational zero-point energy upon complexation $\triangle \mathrm{ZPE}$ (MP2/aug-cc-pVTZ), and the resulting absolute dissociation energy $D_{0}$ for the two most stable $w e_{g}+$ and $w e_{t}$ conformations of the mixed isotopic ethanol/water complex (units of $\mathrm{kJ} \mathrm{mol}^{-1}$ ).

\begin{tabular}{lrrrr}
\hline \hline & $w e_{g+}$ & $w e_{g+}(\mathrm{d} 1)$ & $w e_{g+}(\mathrm{d} 6)$ & $w(\mathrm{~d} 2) e_{g+}$ \\
\hline$D_{e}$ & 26.50 & 26.50 & 26.50 & 26.50 \\
$\Delta \mathrm{ZPE}$ & 8.33 & 8.21 & 7.96 & 6.68 \\
$D_{0}$ & 18.17 & 18.29 & 18.54 & 19.82 \\
\hline & $w e_{t}$ & $w e_{t}(\mathrm{~d} 1)$ & $w e_{t}(\mathrm{~d} 6)$ & $w(\mathrm{~d} 2) e_{t}$ \\
\hline$D_{e}$ & 25.94 & 25.94 & 25.94 & 25.94 \\
$\Delta \mathrm{ZPE}$ & 8.05 & 7.85 & 7.64 & 6.39 \\
$D_{0}$ & 17.89 & 18.09 & 18.30 & 19.55 \\
\hline \hline
\end{tabular}

${ }^{\text {a Electronic dissociation energies } D_{e} \text { calculated at the CCSD(T)-F12/aug-cc-pVQZ level }}$ based on optimized geometries at the MP2/aug-cc-pVQZ level.

change of vibrational ZPE upon complexation accounts for between 6.4 and $8.3 \mathrm{~kJ} \mathrm{~mol}^{-1}$ in the harmonic approximation depending on the isotopic substitutions and the hydrogen donor/acceptor roles. In terms of the two most stable $w e_{t}$ and $w e_{g_{+}}$conformations, the benchmark dissociation energy difference prediction $D_{e}\left(w e_{g_{+}}\right)-D_{e}\left(w e_{t}\right)$ of $0.56 \mathrm{~kJ} \mathrm{~mol}^{-1}$ is translated into a smaller $0.28 \mathrm{~kJ} \mathrm{~mol}^{-1}$ difference between the resulting absolute $D_{0}$-values. A smaller difference of $0.20 \mathrm{~kJ} \mathrm{~mol}^{-1}$ between the resulting absolute $D_{0}$-values for the two most stable conformations of the ethanol-d1/water complex is predicted. These predictions help to explain the fact that both conformations are clearly observed in the far-infrared neon matrix isolation spectra recorded for ethanol-d1/water mixtures.

\section{The effects of weak secondary $\mathrm{CH}$... O hydrogen bonding}

A closer look at these two normal mode pictures reveals that whereas the out-of-plane donor $\mathrm{OH}$ librational mode exhibits an almost localized motion of the bound hydrogen atom almost independent of the dangling $\mathrm{OH}$ group on the water molecule, the in-plane mode donor $\mathrm{OH}$ librational mode can essentially be pictured as a hindered overall $c$-axis rotation of the water subunit. The latter large-amplitude in-plane $\mathrm{OH}$ librational motion of the entire water molecule is therefore expected to be affected more by the weaker secondary $\mathrm{O} \cdots \mathrm{HC}$ hydrogen bond interaction between the terminal $\mathrm{CH}$ group on ethanol and the oxygen lone pair on the water subunit. This has been observed previously for $\mathrm{OH}$ librational motion of hydroxy-group containing molecules in crystalline phases. ${ }^{43,44}$ In a series of electronic structure calculations at the MP2/aug-cc-pVTZ level, the secondary $\mathrm{O} \cdots \mathrm{HC}$ hydrogen bond contact of the $w e_{g_{+}}$conformation has been kept as a fixed parameter in the geometry optimizations and subsequent harmonic force field calculations. The predicted harmonic band origins for the intramolecular donor $\mathrm{OH}$-stretching band origin and the two intermolecular donor $\mathrm{OH}$ librational band origins versus the displacement $R-R_{e}$ from the equilibrium value of the intermolecular $\mathrm{CH} \cdots \mathrm{O}$ hydrogen bond distance are shown in Fig. 5. 


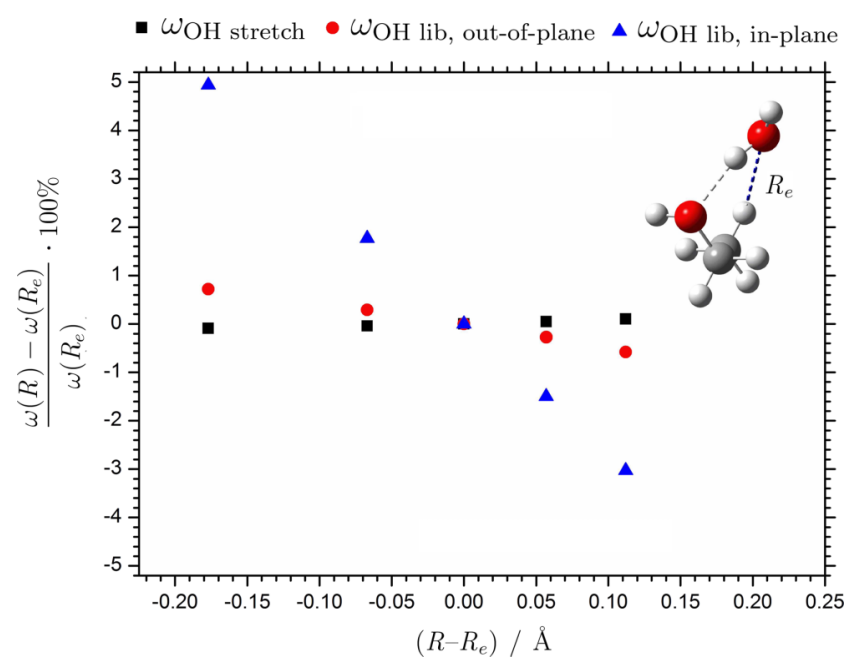

FIG. 5. The predicted relative harmonic band origins $\left(\mathrm{cm}^{-1}\right)$ of the intramolecular donor $\mathrm{OH}$-stretching mode (black squares) and the highfrequency out-of-plane (red circles) and low-frequency in-plane (blue triangles) donor OH librational modes at the MP2/aug-cc-pVTZ level as a function of the displacement $R-R_{e}(\AA)$ away from the intermolecular equilibrium $\mathrm{O} \cdots \mathrm{HC}$ hydrogen bond distance for the most stable $w e_{g+}$ conformation.

The predicted harmonic band origin of the intramolecular donor OH-stretching mode is lowered by less than $1.5 \mathrm{~cm}^{-1}$ when the $\mathrm{O} \cdots \mathrm{HC}$ hydrogen bond distance is shortened by $0.075 \AA$ relative to the equilibrium configuration. This small predicted red-shift of the intramolecular $\mathrm{OH}$-stretching band origin corresponds to a relative spectral shift of less than $0.05 \%$. This almost non-existent dependence of $\mathrm{O} \cdots \mathrm{HC}$ contact is expected as this vibrational mode is highly localized into the intramolecular $\mathrm{O}-\mathrm{H}$ bond of the water subunit involved in the primary $\mathrm{OH} \cdots \mathrm{O}$ hydrogen bond. The absolute harmonic band origin of the intermolecular large-amplitude out-of-plane donor $\mathrm{OH}$ librational mode, on the other hand, is predicted to increase by ca. $2 \mathrm{~cm}^{-1}$ when the secondary $\mathrm{O} \cdots \mathrm{HC}$ hydrogen bond distance is shortened by $0.075 \AA$. The relative blue-shift for this out-of-plane $\mathrm{OH}$ librational mode of $0.4 \%$ confirms the nature of a highly localized vibrational mode associated mainly with the primary intermolecular $\mathrm{OH} \cdots \mathrm{O}$ hydrogen bond. The intermolecular large-amplitude in-plane donor $\mathrm{OH}$ librational band origin, however, is predicted to depend much more significantly on the intermolecular $\mathrm{O} \cdots \mathrm{HC}$ hydrogen bond distance. The harmonic band origin of this hindered overall $c$-axis rotation of the water subunit is predicted to increase by ca. $7.5 \mathrm{~cm}^{-1}$ and thereby relatively blueshifted by $2.5 \%$ when the $\mathrm{O} \cdots \mathrm{HC}$ interaction is shortened by $0.075 \AA$. This more significant dependence on the $\mathrm{O} \cdots \mathrm{HC}$ hydrogen bond distance supports the assumption that the large-amplitude in-plane donor $\mathrm{OH}$ librational mode involving the entire water subunit provides an excellent farinfrared spectroscopic probe for the secondary intermolecular hydrogen bond interaction. The proposed assignments of the bands observed at $320.9 \mathrm{~cm}^{-1}$ and $314.7 \mathrm{~cm}^{-1}$ to the $w e_{g_{+}}-\mathrm{d} 1$ and $w e_{t}-\mathrm{d} 1$ conformations of the ethanol-d1/water complex, respectively, thus seem reasonable in view of the shorter secondary $\mathrm{O} \cdots \mathrm{HC}$ hydrogen bond distance in the most stable conformation.

\section{CONCLUSIONS}

The class of large-amplitude intermolecular donor $\mathrm{OH}$ librational modes for the mixed ethanol-water complex has been observed and unambiguously assigned in the challenging far-infrared spectral region enabled by a dual inlet neon matrix deposition approach and explorative electronic structure calculations. These far-infrared spectroscopic observables confirm directly electronic structure calculations showing that water acts as the hydrogen bond donor in the two most stable conformations of the mixed complex with ethanol. In the most stable and most compact $w e_{g_{+}}$conformation, electronic structure calculations predict that an intermolecular primary $\mathrm{O} \cdots \mathrm{HO}$ hydrogen bond is formed between the water subunit and a lone pair of the oxygen atom on the ethanol subunit with a secondary cooperative hydrogen bond interaction between the terminal $\mathrm{CH}$ group on ethanol and the oxygen lone pair on water. In this most stable conformation, the water subunit forces the ethanol hydrogen bond partner into its less stable gauche conformation upon complexation although the trans conformation is the most stable conformation for an isolated ethanol molecule. The second most stable $w e_{t}$ conformation of the mixed complex having water as the hydrogen bond donor and the acceptor ethanol subunit in its trans configuration is also further stabilized by a weaker intermolecular $\mathrm{O} \cdots \mathrm{HC}$ hydrogen bond. Its nature as a localized motion of the "bound" hydrogen atom makes the high-frequency out-of-plane donor $\mathrm{OH}$ librational mode an excellent spectroscopic probe for the primary intermolecular $\mathrm{O} \cdots \mathrm{HO}$ hydrogen bond energy in a similar fashion as the well-known Badger-Bauer relationship associated with the bathochromic shift of the intramolecular donor $\mathrm{OH}$ stretching band. ${ }^{14}$ The low-frequency in-plane donor $\mathrm{OH}$ librational mode of the mixed ethanol/water complex, essentially a hindered overall $c$-axis rotation of the water subunit, has proven a valuable spectroscopic probe for the secondary intermolecular hydrogen bond interactions as supported by electronic structure calculations. The present findings thus indicate that these large-amplitude donor $\mathrm{OH}$ librational motions in general may be helpful for far-infrared spectroscopic detection of conformations for more complex biological systems where the interplay between multiple intermolecular organic hydrogen bond interactions defines the multidimensional conformational potential energy landscapes of the systems.

\section{ACKNOWLEDGMENTS}

The authors acknowledge Center for Scientific and Technical Computing at Lund University (LUNARC) for the generous allocation of computational resources and the DTU Computing Center (DCC) for access to the High Performance Computing (HPC) services. R.W.L. acknowledges financial support from the Danish Council for Independent Research's Sapere Aude Programme (Grant Reference No. 12-125248).

${ }^{1}$ J. R. Durig and R. A. Larsen, J. Mol. Struct. 238, 195-222 (1989).

${ }^{2}$ J. C. Pearson, K. V. L. N. Sastry, E. Herbst, and F. de Lucia, J. Mol. Spectrosc. 175, 246-261 (1996).

${ }^{3}$ E. E. Fileti and S. Canuto, Int. J. Quantum Chem. 104, 808-815 (2005).

${ }^{4}$ E. E. Fileti, M. A. Castro, and S. Canuto, Chem. Phys. Lett. 452, 54-58 (2008). 
${ }^{5}$ C. Cézard, C. A. Rice, and M. A. Suhm, J. Phys. Chem. A 110, 9839-9848 (2006).

${ }^{6}$ R. Wugt Larsen, P. Zielke, and M. A. Suhm, J. Chem. Phys. 126, 194307 (2007).

${ }^{7}$ M. Nedić, T. N. Wassermann, R. Wugt Larsen, and M. A. Suhm, Phys. Chem. Chem. Phys. 13, 14050-14063 (2011).

${ }^{8}$ M. Nedić, T. N. Wassermann, Z. Xue, P. Zielke, and M. A. Suhm, Phys. Chem. Chem. Phys. 10, 5953-5956 (2008).

${ }^{9}$ I. A. Finneran, P. B. Carroll, M. A. Allodi, and G. A. Blake, Phys. Chem. Chem. Phys. 17, 24210-24214 (2015).

${ }^{10}$ R. Wugt Larsen and M. A. Suhm, J. Chem. Phys. 125, 154314 (2006).

${ }^{11}$ R. Wugt Larsen and M. A. Suhm, Phys. Chem. Chem. Phys. 12, 8152-8157 (2010).

${ }^{12}$ F. Kollipost, J. Andersen, D. W. Mahler, J. Heimdal, M. Heger, M. A. Suhm, and R. Wugt Larsen, J. Chem. Phys. 141, 174314 (2014).

${ }^{13}$ J. Ceponkus, P. Uvdal, and B. Nelander, J. Chem. Phys. 129(19), 194306 (2008).

${ }^{14}$ S. H. Bauer and R. M. Badger, J. Chem. Phys. 5, 837 (1937).

${ }^{15}$ J. Andersen, J. Heimdal, D. W. Mahler, B. Nelander, and R. Wugt Larsen, J. Chem. Phys. 140, 091103 (2014).

${ }^{16}$ J. Ceponkus and B. Nelander, J. Phys. Chem. A 108(31), 6499-6502 (2004).

${ }^{17}$ J. Ceponkus, G. Karlstrom, and B. Nelander, J. Phys. Chem. A 109, 7859-7864 (2005).

${ }^{18}$ J. Ceponkus, P. Uvdal, and B. Nelander, J. Chem. Phys. 133(7), 074301 (2010).

${ }^{19}$ J. Ceponkus, P. Uvdal, and B. Nelander, J. Phys. Chem. A 114(25), 6829-6831 (2010).

${ }^{20}$ A. J. Barnes and H. E. Hallam, Trans. Faraday Soc. 66, 1932-1940 (1970).

${ }^{21}$ J. R. Durig, W. E. Bucy, C. J. Wurrey, and L. A. Carreira, J. Phys. Chem. 79, 988-993 (1975).

${ }^{22}$ J. C. Pearson, C. S. Brauer, and B. J. Drouin, J. Mol. Spectrosc. 251, 394-409 (2008).

${ }^{23}$ T. N. Wassermann and M. A. Suhm, J. Phys. Chem. A 114, 8223-8233 (2010).

${ }^{24}$ M. L. Senent, Y. G. Smeyers, R. Dominguez Gomez, and M. Villa, J. Chem. Phys. 112, 5809-5819 (2000).

${ }^{25}$ J. Andersen, J. Heimdal, and R. Wugt Larsen, Phys. Chem. Chem. Phys. 17, 23761-23769 (2015).

${ }^{26}$ N. Bakkas, Y. Bouteiller, A. Loutellier, J. P. Perchard, and S. Racine, J. Chem. Phys. 99, 3335-3342 (1993).

${ }^{27}$ N. Bakkas, Y. Bouteiller, A. Loutellier, J. P. Perchard, and S. Racine, Chem. Phys. Lett. 232, 90-98 (1995).
${ }^{28}$ S. Coussan, P. Roubin, and J. P. Perchard, J. Phys. Chem. A 108, 7331-7338 (2004).

${ }^{29}$ M. J. Frisch, G. W. Trucks, H. B. Schlegel, G. E. Scuseria, M. A. Robb, J. R. Cheeseman, G. Scalmani, V. Barone, B. Mennucci, G. A. Petersson, H. Nakatsuji, M. Caricato, X. Li, H. P. Hratchian, A. F. Izmaylov, J. Bloino, G. Zheng, J. L. Sonnenberg, M. Hada, M. Ehara, K. Toyota, R. Fukuda, J. Hasegawa, M. Ishida, T. Nakajima, Y. Honda, O. Kitao, H. Nakai, T. Vreven, J. A. Montgomery, Jr., J. E. Peralta, F. Ogliaro, M. Bearpark, J. J. Heyd, E. Brothers, K. N. Kudin, V. N. Staroverov, R. Kobayashi, J. Normand, K. Raghavachari, A. Rendell, J. C. Burant, S. S. Iyengar, J. Tomasi, M. Cossi, N. Rega, J. M. Millam, M. Klene, J. E. Knox, J. B. Cross, V. Bakken, C. Adamo, J. Jaramillo, R. Gomperts, R. E. Stratmann, O. Yazyev, A. J. Austin, R. Cammi, C. Pomelli, J. W. Ochterski, R. L. Martin, K. Morokuma, V. G. Zakrzewski, G. A. Voth, P. Salvador, J. J. Dannenberg, S. Dapprich, A. D. Daniels, O. Farkas, J. B. Foresman, J. V. Ortiz, J. Cioslowski, and D. J. Fox, GAussian 09, Revision D.01, Gaussian, Inc., Wallingford, CT, 2009.

${ }^{30}$ R. Ahlrichs, M. Baer, M. Haeser, H. Horn, and C. Koelmel, Chem. Phys. Lett. 162, 165-169 (1989)

${ }^{31}$ F. Furche, R. Ahlrichs, C. Haettig, W. Klopper, M. Sierka, and F. Weigend, WIREs: Comput. Mol. Sci. 4, 91-100 (2014).

${ }^{32}$ A. D. Becke, J. Chem. Phys. 98, 5648-5652 (1993).

${ }^{33}$ S. E. S. Grimme, J. Antony, and H. Krieg, J. Chem. Phys. 132, 154104 (2010).

${ }^{34}$ C. Møller and M. Plesset, Phys. Rev. 46, 618 (1934).

${ }^{35}$ K. Raghavachari and J. A. Pople, Int. J. Quantum Chem. 14, 91 (1978).

${ }^{36}$ R. A. Kendall, J. T. H. Dunning, and R. J. Harrison, J. Chem. Phys. 96, 6796-6806 (1992).

${ }^{37}$ J. A. Pople, M. Head-Gordon, and K. Raghavachari, J. Chem. Phys. 87, 5968 (1987).

${ }^{38}$ T. B. Adler and H.-J. Werner, J. Chem. Phys. 135, 144117 (2011).

${ }^{39}$ B. J. Ransil, J. Chem. Phys. 34, 2109 (1961).

${ }^{40}$ S. F. Boys and F. Bernardi, Mol. Phys. 19, 553-566 (1970).

${ }^{41}$ V. Barone, J. Chem. Phys. 122, 14108 (2005).

${ }^{42}$ A. Sharma, I. Reva, R. Fausto, S. Hesse, M. A. Suhm, S. K. Nayak, R. Sathiskumar, R. Pal, and T. N. G. Row, J. Am. Chem. Soc. 133, 20194 (2011).

${ }^{43}$ S. Jarmelo, I. Reva, M. Rozenberg, M. Ramos Silva, A. M. Matos Beja, and R. Fausto, J. Phys. Chem. B 112, 8032-8041 (2008).

${ }^{44}$ See supplementary material at http://dx.doi.org/10.1063/1.4937482 for the calculated absolute electronic energies employing the B3LYP, B3LYP-D3, $\mathrm{MP} 2, \operatorname{CCSD}(\mathrm{T})$, and $\operatorname{CCSD}(\mathrm{T})-\mathrm{F} 12$ methodologies with the aug-cc-pVTZ and aug-cc-pVQZ basis sets and the calculated harmonic vibrational zeropoint energy corrections employing the MP2/aug-cc-pVTZ method. 